\title{
Recurrent Adenocarcinoma of External Auditory Canal: A Rare Case Report
} Shreyas Somnath ${ }^{1}$, Suvadip Chakrabarti ${ }^{2}$, Sanjay M Desai ${ }^{3}$ and Sanjay Sharma ${ }^{3}$

${ }^{1}$ Department of Surgical Oncology, D.Y. Patil School of Medicine, Nerul Navi Mumbai, India

${ }^{2}$ Department of Surgical Oncology, R.D. Gardi Medical College and Hospital, Ujjain, India

${ }^{3}$ Department of Surgical Oncology, Sri Aurobindo Medical College and PG Institute, Indore, India

\begin{abstract}
Primary carcinoma of the external auditory canal is extremely rare, with an incidence of approximately one per million populations per year. The commonest presenting symptom is reported to be pain followed by signs and symptoms of chronic suppurative otitis media.

A 28 year old male patient presented with polypoidal mass in left ear occluding external auditory canal since 3 months. Radical excision was done. The histopathology suggested poorly differentiated adenocarcinoma with surgical margins free. Patient received adjuvant radiotherapy ( 25 cycles, 50Gy).

Patient developed recurrence within 6 months for which wide excision of the mass along with excision of external auditory canal and a scalp rotation flap was performed. Patient was given concurrent chemoradiotherapy.

In such cases the need for adequate surgical excision has been stressed by many authors. Parotid gland involvement and perineural involvement are poor prognostic signs, associated with high chances of recurrence after surgical resection.
\end{abstract}

Keywords: Recurrent adenocarcinoma; External auditory canal; Ceruminomas; Scalp rotation flap

\section{Introduction}

Carcinoma of external auditory canal is extremely rare an incidence of approximately one per million population per year. It has an aggressive nature and poor prognosis [1]. Adenocarcinoma of external auditory canal is considered a subgroup under ceruminomas, that arises from glandular elements of external auditory canal. Ceruminomas are classified into 4 distinct subgroups viz- ceruminous adenoma, ceruminous adenocarcinoma, adenoid cystic carcinoma and pleomorphic adenoma [2-4]

Hereby we are describing a rare case of recurrent adenocarcinoma of external auditory canal infiltrating into middle ear, its surgical management with review of literature which to the best of our knowledge has not being reported in literature as a detailed search in PubMed with the keywords recurrent adenocarcinoma, external auditory canal, ceruminomas yielded no such case report.

\section{Case Report}

A 28 year male presented with polypoidal mass in left ear occluding external auditory canal since 3 months (Figure 1). He complained of severe pain, deafness of left ear and pus discharge from the left ear since 3 months. Past history revealed that he was operated by an ENT surgeon 9 months back for left external auditory canal mass and radical excision was done. Histopathology suggested poorly differentiated adenocarcinoma. Surgical margins were reported to be free. Patient also received adjuvant radiotherapy ( 25 cycles, 50Gy).

On examination there was no evidence of any lymphadenopathy. Chest $\mathrm{x}$-ray and USG abdomen showed no abnormal findings. HRCT showed an ill-defined heterogeneously enhancing soft tissue density involving left external auditory canal causing erosion of petrous temporal bone and mastoid, extending to mastoid antrum and middle ear causing infiltration into subcutaneous tissue in post auricular region and abutting left parotid gland (Figure 2). An impression of malignant mass lesion arising from left external auditory canal was made.
Patient was operated with a wide local excision of the mass along with excision of external auditory canal with removal of petrous part of temporal bone (Figure 3). Curettage was done upto the dura. A scalp rotation flap was used to cover the defect (Figure 4).

Histopathology was suggestive of poorly differentiated cerunimous adenocarcinoma. Surgical margins were free. Immunohistochemistry (IHC) was positive for AE1, Vimentin, S100 (diffuse) and suggestive of poorly differentiated adenocarcinoma. Patient was given concurrent chemoradiotherapy and was on regular follow up for 3 months postsurgery.

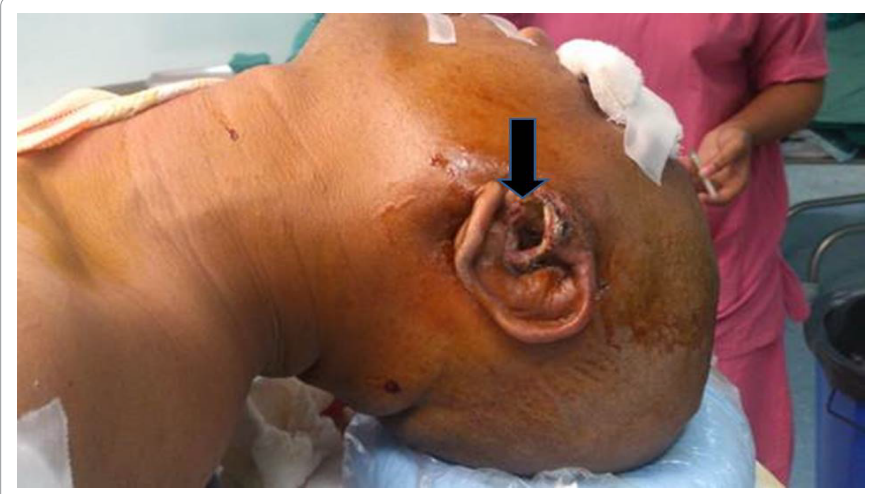

Figure 1: Preoperative picture showing polypoidal mass in left ear.

*Corresponding author: Suvadip Chakrabarti, Department of Surgical Oncology, R.D. Gardi Medical College, Ujjain, India, Tel: +919755093944; E-mail:suvsc@yahoo.co.in

Received June 08, 2015; Accepted June 28, 2015; Published June 30, 2015

Citation: Somnath S, Chakrabarti S, Desai SM, Sharma S (2016) Recurrent Adenocarcinoma of External Auditory Canal: A Rare Case Report. J Mol Biomark Diagn 7: 291. doi:10.4172/2155-9929.1000291

Copyright: (c) 2016 Somnath S, et al. This is an open-access article distributed under the terms of the Creative Commons Attribution License, which permits unrestricted use, distribution, and reproduction in any medium, provided the original author and source are credited. 


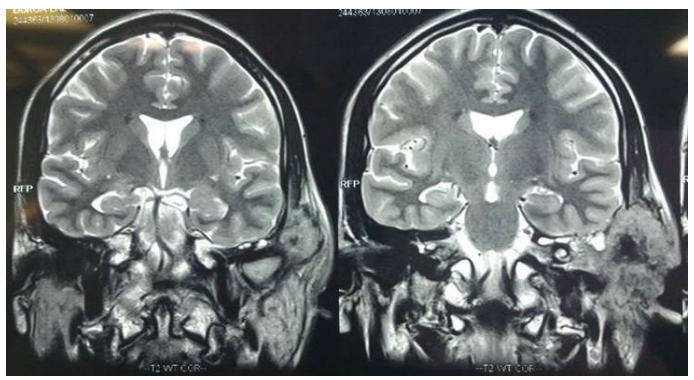

Figure 2: Image showing mass in the left external auditory canal abutting the dura.

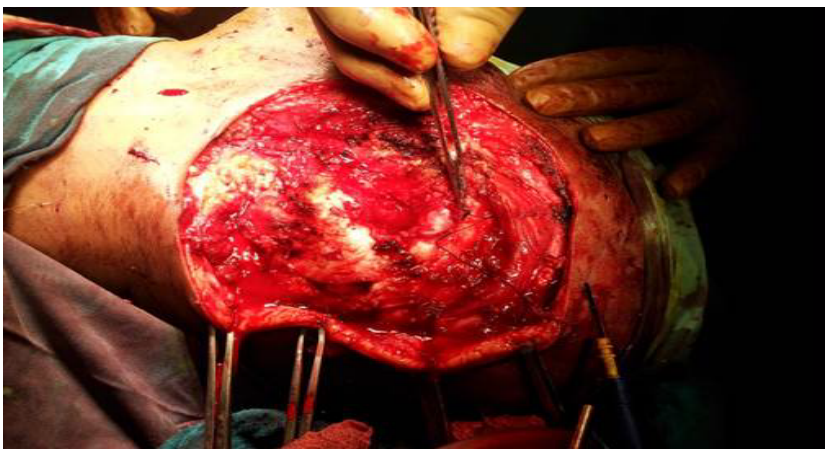

Figure 3: Intra operative picture.

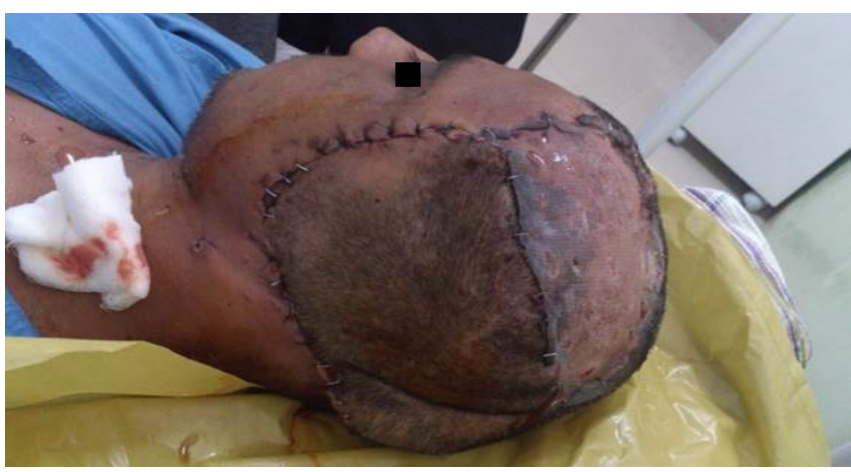

Figure 4: Postoperative picture showing, scalp rotation flap.

\section{Discussion}

Ceruminous glands are modified sweat glands lying deep in dermis of cartilagenous portion of external auditory canal. According to Althaus and Ross, neoplasia arising from the ceruminous glands are quite rare. Habib (1981) reported that these tumours are common in cats and dogs. Hicks (1983) reported that adenoid cystic carcinoma is commonest of rare ceruminous gland tumours. First reported case of external auditory canal adenocarcinoma was in 1943 by Dockerty and Mayo. They used the term adenocarcinoma "cylindroma" type. Hicks has recommended morphological classification of the histology of tumours into 3 types- majority pattern (a moderately well differentiated encapsulated adenocarcinoma), good prognosis (cribriform growth pattern), poor prognosis (predominantly anaplastic growth pattern). Commonest presenting symptom is reported to be pain followed by signs and symptoms of chronic suppurative otitis media as found in the present case [2]. In IHC ceruminous adenocarcinomas demonstrate labeling of the luminal cells with cytokeratin 7 and labelling of the myoepithelial cells with S100 [5]. In the present case IHC was positive for S100.

In such cases the need for adequate surgical excision has been stressed by many authors [6]. Parotid gland involvement and perineural involvement are poor prognostic signs associated with high chances of recurrence of tumours after surgical resection. No consensus exists as to the type of procedure that should be chosen. Some authors advocate en bloc resection, the extent of which is to be determined by pre-operative imaging techniques. Others advocate that surgery should be guided by intra operative findings in a piecemeal manner. Due to close proximity of many vital structures to the temporal bone; en bloc resection has become technically difficult and subject to significant morbidity and mortality. The dense bone of base of skull base is thought to reduce the effectiveness of irradiation therapy. Radiotherapy for these cases is controversial [7]. Hicks states as adenocarcinomas are radiosensitive, as opposed to curable, it should be given to all patients in post-operative period [3].

\section{Conclusion}

Patients with adenocarcinoma external auditory canal can benefit from surgical interventions without significant morbidity or mortality. However, patients with advanced cancer have high recurrence rate despite of adjuvant radiotherapy, suggesting more aggressive surgical approach for complete resection. Although recurrences usually occur within 3 months after inadequate management, some may happen even after 7 years post treatment. Therefore, routine long term follow up is advised.

\section{References}

1. Saunders TFC, Monksfield P (2014) A case of conservatively managed invasive ceruminoma and a review of literature. Case Rep Otolaryngol 2014 897540

2. Kagotani A, Ishida M, Yoshida K, Okabe H (2014) Adenoid cystic carcinoma of the external auditory canal successfully diagnosed by fine-needle aspiration. Diagnostic cytopathology 42: 102-104.

3. Sandison A (2016) Adenocarcinoma, Ceruminous. Head and Neck Pathology 12-5.

4. Varshney H, Taneja V, Taneja MK (2014) Ceruminous gland adenoma. Indian J Otology 20: 41

5. Spielmann PM, McKean S, White RD, Hussain SS (2013) Surgical management of external auditory canal lesions. J Laryngology \& Otology 127 246-51.

6. Takenaka Y, Cho H, Nakahara S, Yamamoto Y, Yasui T, et al. (2015) Chemoradiation therapy for squamous cell carcinoma of the external auditory canal: A meta-analysis. Head \& neck 37: 1073-1080.

7. Homer JJ, Lesser T, Moffat D, Selvin N, Price R, et al. Management of lateral skull base cancer: United Kingdom National Multidisciplinary Guidelines. J Laryngol Otol 130: 119-124. 